\title{
Healthy hands make light work Finger-licking FRESH
}
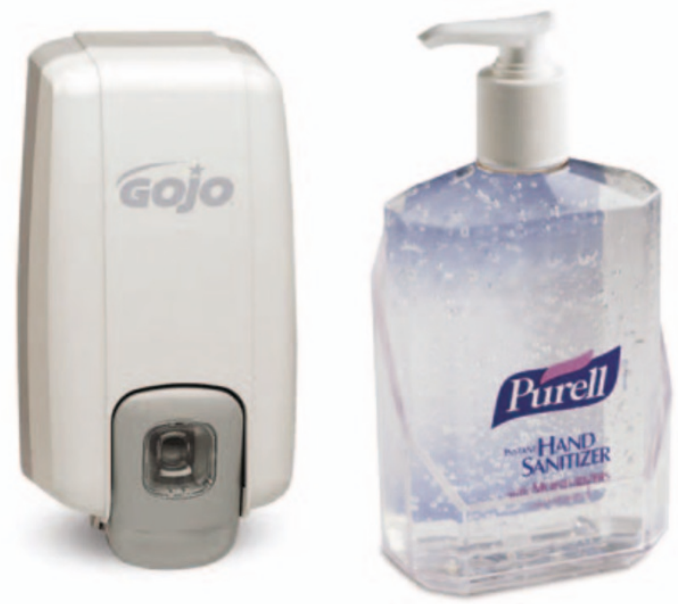

Maintaining clean, healthy hands in the dental practice requires a conscientious approach to skin care. Gojo from Trycare introduce their new skin care routine, comprising Antibacterial Lotion Soap, Antibac Lotion Soap and Purell Instant Hand Sanitizer.

Trycare claim that the fragrance free antibacterial soap kills $99.5 \%$ of most common bacteria in just 30 seconds, but is kind to hands even with frequent use. The Antibac lotion soap has similar benefits combined with an effective degreasing agent.

To complement these products, the hand sanitizer can wipe out $99.99 \%$ of most common microorganisms in seconds, significantly reducing chances of cross infection through the hands. As no water or towels are required to use the Gojo skin regime, it is convenient to use and evaporates swiftly leaving hands feeling soft and refreshed.

For further information telephone 01274881044.

\section{A perfect polish}

Dental pulp can be damaged by high temperatures generated by high speed turbine motors used to polish teeth. Busch cool diamond instruments, now gold-coloured for easy identification, have asymmetrically structured diamond-coated cooling grooves which ensure cooler cutting and no vibration. With enhanced cutting performance

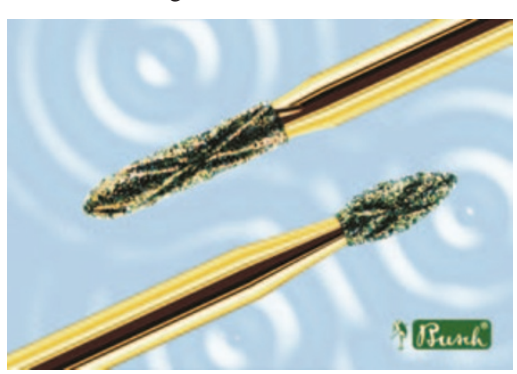

and improved chip removal as well, Busch are confident that their tools, which come in over 70 different shapes and sizes, are ideal for all types of preparatory work.

For more information telephone 00492263860 .

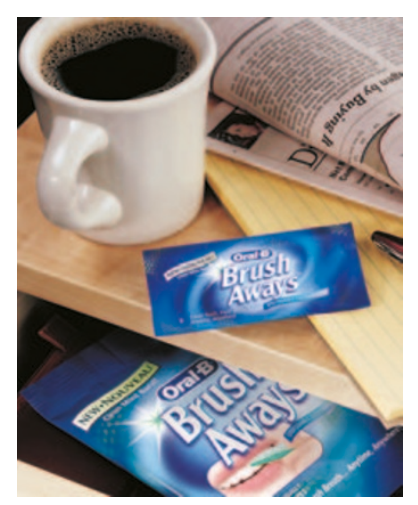

Do your patients complain that they're too busy to worry about oral hygiene? Oral-B believe they have found the ideal solution with new 'Brush-Aways'. Clinically proven to remove plaque, this instant teeth cleaning and breath freshening product complements usual brushing and flossing routines, as it is designed to slip over a finger and be used on the go. Brush-Aways come in small, compact packets to fit into pockets and handbags, and have a refreshing mint flavour.

Samples of Brush-Aways (supplied in a compact dispenser) are available for practices to give away to their patients while stocks last.

Contact your local Oral-B rep.

\section{Get organised}

The recent NICE recommendations mean that patients are now booking appointments even further ahead, so there's no time like the present to order your 2006 appointment books. The British Dental Health Foundation (BDHF) is ahead of the game, launching durable A4 hardbound books available in black, blue, brown, green, grey or red and allowing for appointments from 8am$8 \mathrm{pm}$, six days a week. The books also feature useful contact details for dental organisations and societies, space for advance appointments in 2007 and a handy address and notes section.

Priced at £14.34 for members of the BDHF and £19.12 for non-members (plus VAT and p\&p on all orders), all money raised goes towards maintaining the free information services provided by the BDHF. A number of other products are also available.

Call the resource team on 08707704015 to order.



spring $05 \mathbf{5 1}$ 


\section{marke†

\section{Ulcer ouster}

Mouth ulcers can appear for all kinds of reasons including:

- Stress, physical trauma, irritant agents, hypersensitivity to food stuffs, radio or chemotherapy

- Bacterial, viral or fungal infections

- Haematological and gastrointestinal conditions and nutritional deficiency

- Dermatological diseases like lichen planus, discoid herpes and erythematosas.

Gengigel has created a mouth and gum-care gel based on hyaluronan, which they are confident accelerates the healing process of mouth ulcers. The hyaluronan ingredient aims to reduce the incidence of major ulcers, which unlike minor ulcers occur in regular cycles and take longer to heal.

Through performing a number of structural and physiological functions within the tissues, Gengigel claim that hyaluronan encourages tissue to grow back faster while also assisting in the prevention of re-infection.

For further information telephone Oraldent on 01480862080.

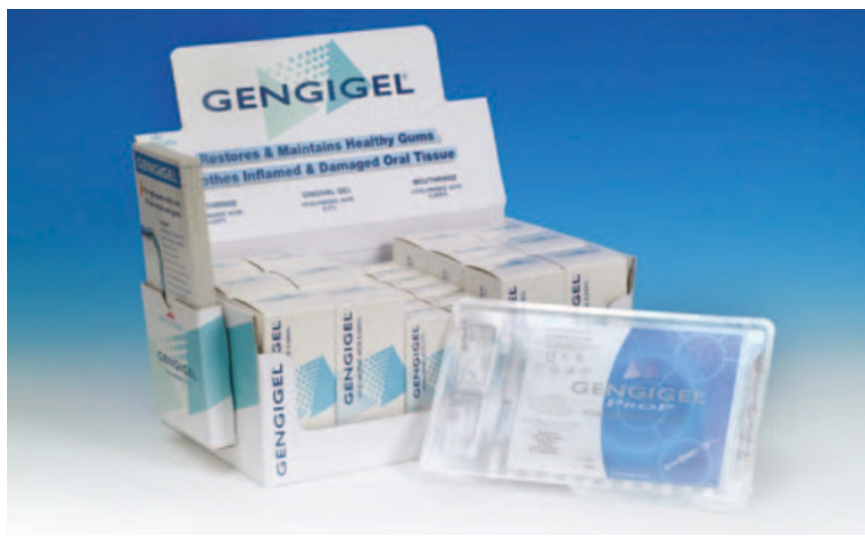

\section{Toothbrushing technique}

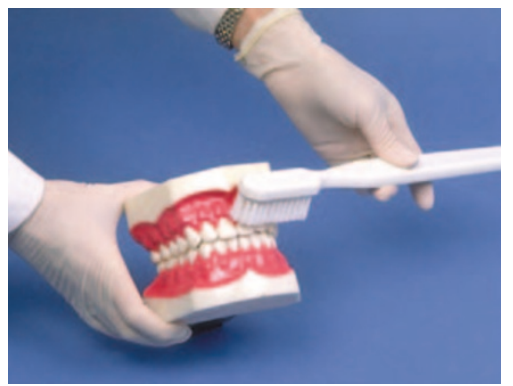

Need to demonstrate good oral hygiene in a clear, simple way? Trycare Ltd provide a larger than life toothbrushing demonstrator model and toothbrush to enable easy chairside demonstration of toothbrushing techniques. The SDI Demonstrator Model and Toothbrush comprises a hinged upper and lower measuring $123 \times 160 \times 102 \mathrm{~mm}$ and made from plastic; the toothbrush is white and $344 \mathrm{~mm}$ long.

More products and ideas are available in Trycare's free catalogue. Call 01274881044 for a copy.
SUPERSONIC

After the success of the original Sonicare toothbrush, Henry Schein is now introducing a newly developed powered toothbrush, the Sonicare Elite. This improved model purportedly combines sonic technology and advanced design to create a high speed bristle motion and a dynamic, fluid cleaning action to ensure optimal cleanliness. Henry Schein is certain that using fif the Sonicare Elite will make a noticeable difference to your oral health.

With strong clinical backing, the manufacturers Philips are keen for dental practices to recommend this product as a worthwhile investment for an experience different to that delivered by any other power brush.

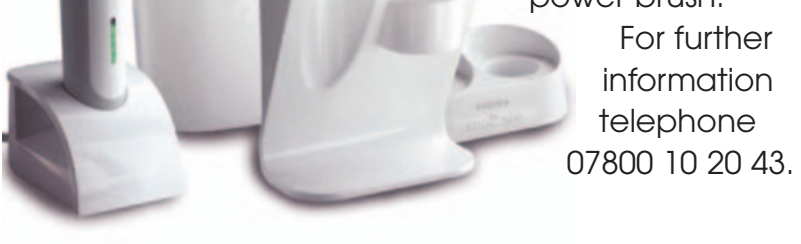

\section{Practical trays}



Set-up, treatment and recycling are all time-consuming activities in the dental practice. In the PractiPal System instruments and accessories are stored in one unit to be processed over and over as required. The system can also be tailored to an individual practice's needs, as the components work together or as stand alone items.

PractiPal procedure trays do not need constant replacing; after use they can simply be upturned to remove loose waste and debris. Only disposable items like cups and dappen dishes need to be replaced. Special security features ensure burs and instruments are protected from damage and causing injury, but all items are easily removable for cleaning and sterilisation before replacing the replenished tray and disposables.

The PractiPal Tray System is made of hard-wearing anti-corrosive plastic to reduce noise during handling; and high walls reduce the risk of accidental injury. The trays can be clipped together for larger set-ups and the dual function Bur/Endo Stand secures files or burs and also includes a file measuring gauge and stop ring positioner.

This product and others are available from Trycare Ltd on 01274881044. 


\section{Surgery furniture}

Three new ranges of cabinetry from Henry Schein promise to accommodate your dental practice's every need: The Praxis, Pacific and Penstock Ranges are tailored towards infection control, computerisation and patient and dental team comfort. A variety of ergonomically designed and finely detailed furniture is available in a range of prices, colours and materials manufactured to last.

Henry Schein claim to work in conjunction with its customer practices as well as highly skilled engineers at every stage of their design process in order to create the best quality products possible.

For further information telephone 08700102041.

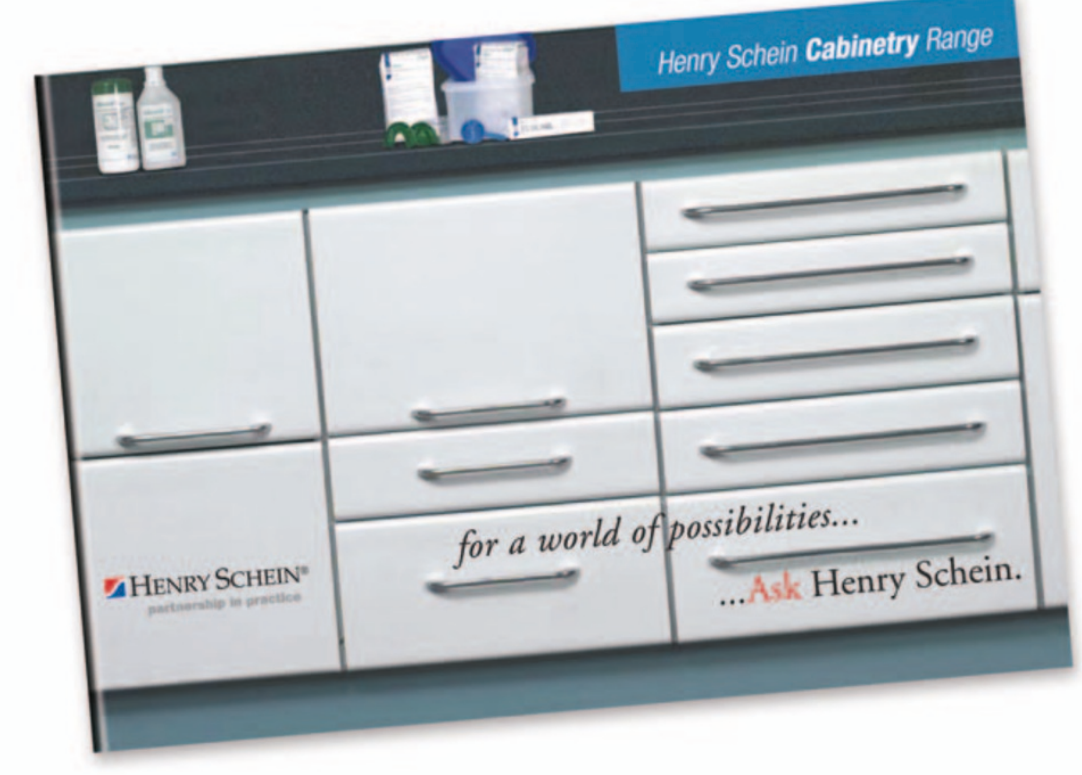

\section{Destroy super bugs}

Sterinis is a brand new product developed in France to prevent the spread of 'super bugs' in hospitals. The device attacks infectious agents with tiny parti-



cles of disinfectant in a dry mist. Produced with the latest technology from aerospace industries, Sterinis can be programmed to disinfect any surface and neutralise infection black spots including those which are tricky to reach.

BES Decon, who distribute Sterinis in the UK, believe the product to be a major breakthrough in the battle to combat the spread of hospital-acquired infections - thought to cause the deaths of over 5,000 people in the UK, and over 90,000 throughout Europe each year. Traditional methods of disinfection and sterilisation are only semi-effective.

Sterinis can provide continuous protection against cross infection and costs £4999+VAT. To order call 08451300237.



Not satisfied with just

producing an excellent range, we now have a selection of tools to help you to help your patients. The TePe Surgery Pack provides an economical way of trialling our interdental brushes. The TePe Communicator is invaluable for oral hygiene education and demonstration, and of course, surgery display materials are also available.

For more information please call Molar Ltd on 01934710022 or email: info@molarltd.co.uk

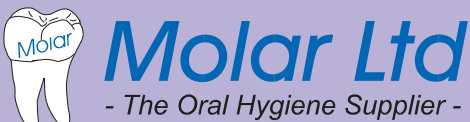

